\begin{tabular}{|c|c|}
\hline 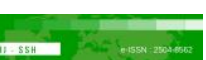 & Malaysian Journal of Social Sciences and Humanities (MJSSH) \\
\hline Malaysian Journal of & Volume 6, Issue 7, July 2021 \\
\hline (mJ-ssH) & e-ISSN : 2504-8562 \\
\hline & $\begin{array}{l}\text { Journal home page: } \\
\text { www.msocialsciences.com }\end{array}$ \\
\hline
\end{tabular}

\title{
Comparison and Contrast between Bourdieu's Theory of Practice and Shamsul's Two Social Reality Approach in the Portrayal of Identity
}

\author{
Sharon Regina Vega ${ }^{1}$, Sivamurugan Pandian'1, Nur Hafeeza Ahmad Pazil ${ }^{1}$ \\ ${ }^{1}$ School of Social Sciences, Universiti Sains Malaysia (USM), Penang, Malaysia
}

Correspondence: Sivamurugan Pandian (psiva@usm.my)

\begin{abstract}
This paper analyses Bourdieu's Theory of Practice, the concept field and habitus and Shamsul Amri's Two Social Reality, the concept everyday- defined and authority-defined as both theories that function as analytical tools and have similar narratives based on the macro/micro and structure/agency linkage. A comparison and contrast of both theories were analysed to further understand the use of each theory. Findings within the article show both theories have a structural or authoritative emphasis however the theories differ in functionality with Bourdieu's "Theory of Practice" focusing on power dynamics and social class through direct link between the habitus, field and capital whereas Shamsul's Two Social Reality focuses on the formation of identity and ethnic dynamics in Malaysia based on the effect of colonialism in the authority-defined and everyday-defined sphere. The main goal of this paper serves to highlight both theories and its application when analysing and tackling different social phenomena and narratives in future research.
\end{abstract}

Keywords: theory of practice, two social reality, structure, identity

\section{Introduction}

Bourdieu's construct of the 'Theory of Practice' are taken from sources such as Marx, Durkheim, Weber, Saussure, Wittgenstein, Benveniste, Canguilhem, phenomenological and structuralist traditions (Harker, Mahar and Wilkes, 1990). Bourdieu primarily takes inspiration from Levi-Strauss's structuralism and focuses on the mental constructs that underpin the appearance and functions of society caused from actual practices of individuals (Mehdi et al, 2014; Lacroix, 2012). A similar idea is expressed using insight from Marx and Durkheim in which interest among groups are expressed in symbolic struggles, the power certain groups obtain to impose their knowledge and view of reality onto others is translated into Bourdieu's Theory of Practice using the field and habitus concept (Scott, 2008).

Shamsul Amri's 'Two Social Reality' was formulated in 1995 when presenting the Malaysian experience as a case study, in regards to identity formation and contestation of the ever-changing culture scape, this theory was influenced by works such as (Sweeney, 1987; Ong, 1977; Said, 1978; Hirschman; 1985, $1986^{1}$ ), and was further defined through Shamsul's reflection on the construction of social scientific knowledge in Malaysia, first utilised in the working paper "Australia in Malaysia's Worldview" in a Conference on Australia-Malaysia Relations held by the Centre for Malaysian Studies, Monash

\footnotetext{
${ }^{1}$ A variety of articles addressing the construction of racism and racial categories in Malaysia by Charles Hirschman in 1985 and 1986.
} 
University, Melbourne on 20 April 1995 that has since been published in the conference proceedings in 1996 (Shamsul, 1996a, pp.476-477). The two social reality approach is able to provide balanced attention and examination of the realities separately based on the authority-defined and everyday-defined concept (Shamsul, 1996a, p.479).

As shown, there are several similarities and differences between Bourdieu's theory of practice and Shamsul Amri's two social reality with both functioning as analytical tools focusing on macro-micro levels and understand the concept of identity hence drawing similar parallels in its focus. However, differing in application with Bourdieu's concept of the field and habitus being seen as intertwined and typically focusing on the agency or disposition of the individual within the structure while Shamsul Amri's authority-defined and everyday-defined are separated or exist side by side as structures refer to individuals or institutions of power while agency refers to everyday individuals used to illustrate the social power unique in Malaysia based on colonial knowledge formed during the colonial era.

\section{Theoretical Background}

\section{Bourdieu's Theory of Practice}

Pierre Bourdieu's theory of practice is used to bridge the macro and micro levels which presents the connection between the individual and social processes (Tsekeris \& Lydaki, 2011). Turner and Wainwright (2003) stated Bourdieu recognizes that individuals have agency through practice but it is done under the powerful role of institutions and resources which shape, constrain and produce human agency. The concept 'practice' refers to human activity which constructs individuals as social beings and the world around them. Through human activity individuals internalise cultural symbols and meaning which are transformed and reproduced in the social world (Kupari, 2016).

Theory of practice focuses on the concept of reflexivity, dualism or objective/subjective dichotomy. Identity is formed from the individuals understanding of social relations or behaviour within the social sphere. Practice is often framed as routinization in day-to-day activities that contribute to social structures of power such as economic, politic, social and culture. These actions are done within the limits of the individual and disposition held within the social space (Kupari, 2016; Goetze, 2017; Bottero, 2010).

Pierre Bourdieu's concept of the field refers to social arenas, cultural production and its relations, as 'social fields' are governed by specific values and rules that are eventually internalized by the actor. The habitus references the existence of a system of dispositions based on previous experiences allowing them to structure specific behaviour within the situation (Scott, 2008). Habitus is shaped by relations that unite these structures and practises which produce structured dispositions henceforth producing structured actions that create objective structures (Bourdieu, 1984).

The concept of 'field' contains history and as such there is meaning in its framework based on the differentiated society making it sites of reproduction and transformation interacting with collective and social structures (Hilgers \& Mangez, 2014; Block, 2013). Fields can be seen in two ways; as a power arena based on the struggle for power to maintain their positions and a cultural field based on rules, institutions and categories which produce authorised activities and practices (Pirnajmmudin \& Heidari, 2013; Ngarachu, 2014, Shusterman, 1999). The research is based on cultural fields where structures have rules complied by the individual or group within society.

Within this concept the dominant actors give meaning to hierarchical relations within their field positions. The dominant actor can preserve the structure and rules of the field or change them using capital based on more field-specific practices of everyday interactions (Singh, 2016). They can also be seen as recipients to these structures they are not able to control and accept, Bourdieu uses the term 'illusio' based on the relationship actors have from formation of pre-reflexive beliefs that ensures their conformation to the rules and set condition of their membership of their respective society (Lacroix, 2012; Hilgers \& Mangez, 2014). Such as a judge carrying out the law by setting punishments and sanction by displaying their authority within the positions making them the dominant actor within the 
field. Society has to ensure they follow the rules that have been enforced. Although focus is placed on objective structural relations, the field is made up of other agents and their dispositions between the habitus and field. This form of identity among the actors interpreted into classifications and qualifications (de Nooy, 2003). This indicates there are various structures embodied that produces a specific individual, this is taken from Foucault's idea of productive nature of power and its effect on the environment (Clarke, 2000). In each field individuals compete for power in the form of capital that is determined by logic of said field (Kupari, 2016). Identity within fields is based on the meaning of human action and understanding the history and social trajectory of the individual (Serban, 2011).

The field constrains groups while the individual conditions the habitus, in other words the field constitute the habitus (Ritzer, 1999). Despite this the habitus is not fixed and changes according to their dispositions within the field. This would mean the objective conditions for the material and social environment are not the same for every generation. Therefore, creating constraint within the habitus as they are based on objective conditions that although is based on agency is also fixed within the practices that support the structure (Harker et al, 1990). Habitus is part of the socialization process in which we experience, understand and categorise past events that develop from childhood into perceptions that teach us how to view and interact with our reality and most importantly, appropriately in different contexts (Jones, 1997; Swartz, 2012). The habitus can be seen as micro level behaviour of the everyday experiences within the individual where prior stock knowledge allows them to make decisions regarding their membership group through explanation of practices and cultures. This is because the habitus as mentioned is a product of history therefore produces individual and collective practices which manifest itself in the form of rules and norms (Bourdieu, 1990). This comes from the concept of experience which rescues habitus from social determinism, as the dispositions are subjected to new experiences they modify and reinforce the structure (Cockerham, 2005). Identity within the habitus can be summed up as dispositions of the individual sharing the field containing shared cultural context often links individual history or socialised subjectivity where cultural structures shape behaviour, beliefs and thoughts (Adams, 2006; Bourdieu, 1993; 1977).

Bourdieu's concept of habitus allows an understanding of ethnic identity and relations as it focuses on lived experiences and practices of the individuals within the group (Spencer, 2006). Therefore, shaping social identity through embedded practices that emphasize collective agency such as attitude, self-worth and awareness of individuals within the class (Savage, 2000; Reay, 1998; Skeggs, 1997). Individual identity is based on self-knowledge of the habitus that has been understood as self- revelation of social determination leading to genuine awareness (Serban, 2011).

\section{Shamsul Amri's Two Social Reality}

Shamsul has formulated the two social reality as an analytical tool used to understand the influence of ethnicity in shaping consciously or unconsciously the complexity of Malaysian identity formation (Shamsul and Athi, 2015, p.268). The formation of identity within the two social reality is first introduced by Shamsul (1996a, p.477) when explaining the approach through two concepts, the authority-defined and everyday-defined social reality. The authority-defined is by people who are part of the dominant power structure while the everyday-defined is experienced by the people in their everyday life with both concepts existing side by side at any given time (Shamsul, 1996a, p.477; Shamsul, 1999, p.33; Shamsul, 2001, p.365).

Woven and embedded into these social realities is social power, which can be articulated into various forms such as the majority-minority discourse and state-society contestation. In concrete terms this would involve social collectives such as religious, environmentalist or nationalist groups, literary groups, professional groups, scholar-administrator academicians, political parties, NGO's, trade unions, charity associations, the intelligentsia, academia. The discourse takes both written and oral forms usually by various dimensions in regards to the idea of "social justice" in its reflection of the inherent unequal social power found rooted within the two social reality contexts (Shamsul, 1996a, p.477; Shamsul, 1999, p.33; Shamsul, 2001, p.365; Shamsul \& Athi, 2014, p.268). 
The framework provides conceptual and empirical tools, as an alternative analytical device when examining the internal dynamics of ethnicity and identity formation in Malaysia. It emphasizes the defining role colonial knowledge ${ }^{2}$ has in shaping the Malaysian landscape of modern knowledge production and finally provides understanding of the significance of the social mobility in regards to its material base when reshaping ethnicity and identity emphasizing on inter-ethnic and intra-ethnic dimensions (Shamsul \& Athi, 2015, p.268).

The interconnected and dialectical nature of the relationship between the authority-defined and everydaydefined social reality, which has its material basis, is often ignored or unexamined. This is often the result of a tendency to disconnect, on one end of the spectrum 'social theory', and the other 'public intellectual life', and the 'moral concerns of real people'. The two social reality approach is able to capture the macro picture and the micro detailed dynamics in a more balanced manner, which helps construct narratives and arguments at the macro and micro levels, although one might highlight only one part of the social reality. This approach also encourages the voices of the social actors to speak openly about their experience in contrast to the authority-defined one, which is based on observation and interpretation (Shamsul, 1996a, p.479).

The authority-defined context is based on debates and discourses that have been designed, systematised and recorded. Having taken place in the past or present, within and between the government and nongovernment collectives, amongst the members of the intelligentsia and within the sphere of realpolitik. Authority-defined is based on a variety of themes and issues that are major and minor in nature, involving various social groups. This context is textualized both in published and unpublished forms, with some being drawn up into "official policies" or written as "academic publications". Hence the text of authoritydefined even if verbal is always documented in written form (Shamsul, 1996a, p.478; Shamsul \& Athi, 2014, p.268).

The everyday-defined context is based on personal experiences; hence it is not meant to be systemised or position as a pre-determined macro-objective. The discourse is usually disparate, fragmented and intensely personal conducted mostly orally therefore it is not textualized for future reference except occasionally by researchers, such as anthropologists or historians who would have tape-recorded or written down, as ethnographic notes, these "personal narratives". Despite what each narrative represents or is accepted by society it is usually considered an individual or personal contribution. As such it remains a subjective "text" often considered as "unrepresentative" of the empirical reality or "truth," not dissimilar in status with the legally unacceptable "hearsay" evidence (Shamsul, 1996a, p.478; Shamsul \& Athi, 2015, pp.268-269).

\section{Theoretical Analysis}

\section{How does Bourdieu and Shamsul Portray Identity?}

The Bourdieusian view of identity is based on discursive constructions and reflexivity of the self within limits of routine practice. Bourdieu relates objective relations of material and symbolic power to practical schemes (Bottero, 2010), showcased in the concept "social class" where shared cultural style which are predisposed, consciously and deliberately contributes to class reproduction (Sallaz \& Zavisca, 2007; Fabiansson, 2015). This is formed by the use of capital in correlation with field and habitus, the value given to capital in regards to the social and cultural characteristics of the habits while the field is bonded with the objective power relations containing material base (Harker et al, 1990).

Shamsul views identity as four critical challenges; the first are conceptual challenges in how identity is perceived. Whether identity is 'static' in being ready-made, given, taken for granted or in a dynamic

\footnotetext{
${ }^{2}$ Colonial knowledge refers to knowledge of ethnic groups origins during the colonial era that have been institutionalised, applied and embedded into official bureaucratic tools and public policy formulations such as through the census, land enactment, birth certificates, identity cards, vernacular schools' systems, etc. These classifications have continued to the post-colonial that have extended these racial categories into physical and cultural markers (Shamsul and Athi, 2015, p. 267).
} 
manner identity is viewed as an ever-changing phenomenon. Second is the task of describing and explaining the emergence of consolidation and change of identities over time. Third, the 'analytical challenge' based on social theory within academic analysis on themes of identity based on functionalism, structuralist and post-structuralist. Fourth, the authorial challenge based in the form of 'objectivity vs. subjectivity' struggle in which the individual is based politically on an identity struggle (Shamsul, 1996a, pp.476-477).

\section{Comparison between Bourdieu and Shamsul}

Bourdieu's theory of practice' and Shamsul's two social reality depicts the structure-agency approach which has a basis in social power. Structure-agency was found in the 1970's from the philosophical debate in regards to the man/world relationship. The structure-/agency critique is typically used from past structuralist approaches such as Levi Straussian structuralism and Parsonian Functionalism which sates individuals are unable to affect social structure but still acknowledge individuals as active and reflexive (Lacroix, 2012, pp.4-5). Both theories tend to have a structural emphasis, this approach was drawn from scholars such as Emile Durkheim, Talcott Parsons and Louis Althusser which postulates individual actions originate from social institutions (Vandenberghe, 2005, p.228). The term structure is capricious in its meaning regarding infrastructure or principles of society explaining formal features of society (Lacroix, 2012, p.5). The structural emphasis has a lot of basis in Durkheim's work "The Rules of Sociological Method" which focuses on structure within society and its external constrains on individual activities, the structural properties presented here have existed before the individual had become a member of society and will continues to persist after them. The emphasis is on structure over agency with the belief that actions cannot be explain by human behaviour (Kipo, 2013, p.21). This idea can be further reiterated through social facts which are recognized as power of external coercion (Tan, 2011), they are considered things 'sui generis' that effect or create human activities that have become a product of human behaviour.

The theory of practice depicts the field (structure) constituted within the habitus (agency), this means actors within the habitus are often affected by the fields they are located in and habitus constrained to. In Bourdieu's view of structure and agency; structure is seen as the sustained relationship between schemes and resources known as mental structures. Mental structures refer to a culture which has been constructed according to those structures (Sewell, 1992). This idea of structures having predisposed functions in which practices and representations can be objectively adapted to their outcomes without express mastery needed for attainment (Bourdieu, 1990). This is known as structuring structures which Bourdieu states is a form of 'social, cultural and ideological world' that are interconnected and individuals share membership in those categories. These structures are not seen as direct forms of interaction from the individual themselves but have been constructed from previous eras of interactions and have emerged as such a structure with very little relevance to current individuals and their situations (Bourdieu, 1977).

This idea is also illustrated in Parson's Kantian dualism; relationship between institutionalised norms at societal level and internalization of norms at personality level. This form of dichotomy is based on external coercion versus individual utility based on previous conditions and rules (Sciulli \& Gerstein, 1985). Agency refers to individual freedom and the ability to make decisions without constraint. Bourdieu views agency as individuals who occupy positions within a field based on their interactions have limited range of actions and options. They are seen as a double structuration as social structure and disposition of individual agents are interrelated into one another. The concept here is based on agents confined to the constraints of the habitus which is based on culture of the group or class the individual belongs to. Culture in this sense is reference to collective history of the group and the disposition of the group within the structure and the habitus (Harker et al, 1990). Bourdieu believes agency has a certain amount of autonomy which they can determine themselves but the emphasizing on structure found in habitus and field (Cockerham, 2005).

Shamsul's two social reality shows a clearer distinction between both realities, although both concepts are intricately linked when influencing or shaping the other, they are rarely similar with the everydaydefined being experienced while the authority-defined is observed, interpreted and imposed with both 
being meditated through social class position (Shamsul, 1999, p.33; Shamsul, 2001, p.365; Shamsul and Athi, 2015, p.268). In most cases of identity, often the authority-defined discourse is favoured over everyday-defined as it is assumed the authority (Shamsul, 1996a, p. 477, p. 479). With the former being perceived as scientific, objective, and authoritative, whereas the latter is personal, baseless and shrouded with emotion (Shamsul, 2012, p. 13).

This over-prioritisation has created issues in the discourse of identity as a way to organise social differences in society that often leans towards ethnic categorisation creating authoritatively applied identities that significantly impacts individual experiences in everyday life. These ethnic categories exist on an individualistic level based on the daily interactions among members of society from members of one ethnic group to another (Shamsul, 2012, p.14). Shamsul (1996a, p. 481) believes the influence of identity in authority-defined is built on the scientific knowledge in Malaysia that is not value free. This is generally seen as the ethnicization of knowledge that highlights the hidden social justice agenda within the construction process. This showcases two main assumptions which guide the authority-defined context; first a tendency to generalise where ethnicity is based on a blanketed identification of each category which has been dubbed by Levine (1999) as a 'cognitive approach to ethnicity' in which each ethnic category is homogeneous in nature and exist separately from other ethnic categories. Second, all ethnic groups in society are perceived to 'fit' into a specific category which creates a default system of ethnic categorization operated by the authorities. The dynamics of ethnicity of an ethnic group is expected to occur within the boundaries of an ethnic category and does not spill over to another neighbouring category (Shamsul, 2012, p. 12).

This results in a few problems such as the issue of ethnocentrism present in the majority ethnic group formulated in a prioritised authority-defined context (Shamsul, 2012, p.16). Ethnicities which exist in the 'in-between' space of ethnic categories such as mixed individuals have little to no acknowledgement from the authority-defined level which often resulted in minority groups stemming from amalgamations as part of the assimilation process are left marginalised (Shamsul, 2012, p.14). The unbalanced relationship between the two social realities if left unchecked would affect our ability to see the whole picture holistically (Shamsul, 2012, p.13).

Both theories show there is more focus on the structure or authoritative view of identity than there is in the agency of the individuals themselves. This usually manifest in the modern state's effort to inscribe their citizens into a classificatory grid; to identify and categorise in relation to gender, religion, propertyownership, ethnicity, literacy, criminality, or sanity to sort out individuals in relations to them. This includes the power to name, identify, categorize, state what is what and who is who. The state becomes a powerful identifier in being able to create identities as it has the material and symbolic capital to impose those categories and classificatory schemes which all actors within the state must refer to (Brubakar, 2000, pp.15-16).

\section{Contrast between Bourdieu and Shamsul}

The main difference between both theories is its purpose of functionality in addressing the macro-micro context. Bourdieu's theory of practice places more emphasis on the structure-agency approach while Shamsul's two social reality is based on the macro-micro linkage. The use of macro-micro sometimes overlaps into the structure-agency debates, they are focused on the level and scale analysis while the structure-agency debate focuses on power of systems and individual interactions (Carlsnaes, 1992; Hay, 2002; Layder, 1994).

Hence Bourdieu's theory of practice use of the field and habitus has a similar narrative to the Structure and Agency model, therefore emphasizing social class and power dynamics. This is seen with other concepts the field and habitus further support such as symbolic power and various forms of capital (economic, cultural, social and symbolic) (Harker et al, 1990).

Bourdieu's focus on the field and habitus presents as theory for dialectical analysis of practical life that presents an interplay between personal economic practice and the external world history and social practices (Harker et al, 1990). The concept 'symbolic power' came from the insights of Marx and 
Durkheim by examining the class interests and its expressions in symbolic struggles which is the power to dominate disadvantaged groups and the exercise of its symbolic violence in which the power to impose the principles of the construction of reality on others (Bourdieu, 1997c, p. 115; 1997b, p. 165; 1971; 1973). Also known as symbolic systems it acts as instruments of knowledge and domination which make possible a consensus within the community as significance to the social world and contribute to the reproduction of the social order (Harker et al, 1990). This concept is unique to the theory of practice which uses the context of real -lives using the habitus while incorporating the theory of domination that exists within social fields (Di Maggio, 1979).

The struggle between symbolic systems to impose a view of the social world defines the social space which people construct their lives which Bourdieu considers the symbolic conflicts of everyday life in the use of symbolic violence of dominant power (Bourdieu, 1997c, p. 115). Social space is characterized as a space for status groups of different lifestyles. Symbolic struggle can be seen in two forms; objectively through representations of the individual or collective in showcasing a specific type of reality and subjectively through strategies of self-representation or by changing categories of perception and appreciation of the social world (Harker et al, 1990).

Bourdieu (1997a, p. 74) believes all agents uphold legitimacy and existence of the fields, however individuals who are not equal playing ground tend to use different resources available to them to better their positioning within the field in the form of capital (economic, cultural, social and symbolic). This further contributes to the identification of individuals within social existence as defined by difference, legitimate hierarchies and inequality. The connection between field, habitus and capital is direct, the value of capital factors in social and cultural characteristics of the habitus while the field is bonded by objective power relations which have material base (Bourdieu, 1984; Harker et al, 1990). The relationship between the habitus and field being a product of history and at the same time a product of the field of forces (Harker et al, 1990).

Bourdieu (1978, p. 178) provides a broad definition of capital, it acts as a social relation within a system of exchange with its term extended to all goods, material and symbolic without distinction that presents themselves as being prized in social formation. Capital is also seen as the basis of domination, as various types of capital can be exchanged for one another (Harker et al, 1990). Among the most common conversion capital is made into is symbolic capital as this form allows the capital to recognized as legitimate, this takes the form of an individual or class status of prestige to be recognized as an official authority. Giving them power to create an official version of the social world having a known and recognized identity which in turns confers economic and cultural capital (Harker et al, 1990).

Economic capital, refers to money, land, house and other properties. The agents try to gain more properties to have a higher social status (Storey, 1990, p. xi). Cultural Capital is to is a desire to accumulate or gain things which are culturally valued in order to gain higher social status or socially valued area of practice this is manifested into three area; incorporated form, institutional form and objectified form (Pirnajmuddin \& Heidari, 2013, p.741; Sallaz \& Zavisca, 2007, p. 24). Cultural capital is the culture of the dominant group which controls the economic, social and political resources. In the field and habitus narrative both cultural and economic capital are expressed in the same way of institutions with economic institutions favouring those with economic capital while educational institutions favouring those with cultural capital in the form of habitus of the dominant cultural fraction. The dominant habitus being the form of economic or cultural capital that is adopted by their respective institutions (field) as an effective means to act as a filter in the hierarchical processes (Harker et al, 1990). Social capital is the network of relationships among members of a groups which provides them social value or credit. Bourdieu reduces these inter-personal relations to social capital which can be mobilized for profit, power and resources (Lahire, 2015, p. 98).

Shamsul's two social reality functions as an analytical tool in deciphering identity formation and ethnic dynamics within Malaysia based on aspects of colonialism, colonial knowledge and how categories and classification introduced during the colonial era have been naturalised into the Malaysian social life from the everyday-defined and authority-defined perspective (Shamsul, 1999, p. 3). This is seen when 
examining the themes; 'Nation', 'National identity', 'Nations of intent' and 'Small Majorities' (Shamsul, 1996a, p. 481).

The theme national identity has past and present implications resulting in social categories such as race (the biological and social component) and nation (localised worldview stemming from colonisation in substituting a traditional system to a Western based one).This introduced bureaucratic practices of census-taking which has helped reinvent, consolidate, and evolve racial categories which functioned at the authority-defined level, this influenced the everyday-defined level racial categories such as Malay, Indian, Chinese and Others mattered very much for individuals to take advantage of the colonial bureaucracy making this critical for everyday existence (Shamsul, 1996a, p.482).

The nation takes a new twist after independence that has been phrased into 'national integration', 'national unity' and 'national identity' at the level of authority-defined social reality based on bumiputera ${ }^{3}$-dominated cultural principles and policies documented within the Malaysian Constitution framework . This bumiputera-defined identity has privileged many aspects of bumiputera culture as the core of Malaysian ethnic identity while recognizing other ethnic groups (Shamsul, 1996a, p. 483; Shamsul, 1996b, p. 323; Shamsul, 2013, p.23). At the everyday-defined level the authority-defined identity has been challenged by three groups; the non-Bumiputera, non-Muslim Bumiputera and Islamic Bumiputera group in which all have their own vision of how identity should be based on a particular framework. In this case the non-Bumiputera rejects Bumiputera based and defined cultural principals in favour for pluralistic ones where they are accorded equal position to Bumiputera (Shamsul, 1996b, p. 323; Shamsul, 2013, p. 23; Shamsul, 1996a, p. 480). This again shows the contestation other groups have as their everyday-defined context of identity has been affected by the authority-defined prompting change from a bottom-up approach.

Nation-of-intent is a less defined idea of the 'nation-state' in regards to territory, population, language, culture, symbols and institutions. The idea is shared by individuals who perceive themselves as members of the nation and unites them. Nation-of-Intent implies radical transformation of a given state and its exclusion of certain groups of people. It may imply the creation of a new state but not necessarily aspire for political-rule on individuals advancing their nation-of-intent. The concept is an inclusive construct that has been employed as a political platform in voicing opposition or to challenge the nation's view. (Shamsul, 1996b, p.328; Shamsul, 2013, p.6). The concept is similar to Anderson's concept of the 'imagined political community' which members of the community may not meet or hear from most members yet have constructed a certain image of the community (Shamsul, 2013, pp. 6-7). Shamsul (2013, p. 7) describes the nation-of-intent as positive, proactive, non-deterministic and forward-looking, such as becoming a programmatic plan of action in real politic. This is evident within the Malaysian scope where nation-of-intent has developed from the historical context of anti-colonial and post-colonial era. The nation-of-intent depicts a nation state that is being constantly constructed and reconstructed through the involvement of citizens becoming the bridge between authority and everyday-defined idea of the nation (Shamsul, 1996b, p. 328; Shamsul, 2013, p. 6). The concept is also analytically useful in understanding contradictions within the general discourse on 'nationalism', 'nationalist ideology' and 'nationhood' in the societies of emerging industrial economies by separating the authority defined nationof-intent from the everyday forms of the citizens in articulating interest and coming to terms with each social reality (Shamsul, 1996b, p. 347).

The tension between the authority-defined top-down approach and everyday-defined bottom-up approach has been the cause of tension for the Malaysian government. Resulting from the history and demography of the pluralistic society with no absolute majority in Malaysia that has developed competing groups called small majorities that has long and short term sociological and political involvement (Shamsul, 2013, p. 16). This focus is placed on the ethnic and non-ethnic debate as contestation in the form of bargaining and negotiation of the various policies and implementation in regards to education, language and cultural policy (Shamsul, 2013, p. 19). Small majorities are based on the informed conduct of social processes and inter-group relations in the country. There are two meanings

\footnotetext{
${ }^{3}$ The words "bumiputra" and "pribumi" both words loaned from Sanskrit, bumi means earth or soil while "putra" is translated to "prince" or polite reference to son. In the Peninsular Malaysia the term Malay and bumiputera are used interchangeably as they are the majority (Siddique and Suryadinata, 1981, pp. 662-663; Fernandis, 2000, p. 263).
} 
regarding the 'majority' with one focusing demography of the Malay/Bumiputera majority and the second referring to economic and wealth ownership discussing the Bumiputera quota struggling to fill in $30 \%$ while $70 \%$ is provided to others in the form of family businesses or large corporations (Shamsul, 2013, p. 17).

\section{Conclusion}

Bourdieu's theory of practice and Shamsul's two social reality both function as analytical tools as a means of communicating a theoretical stance which is the macro-micro linkage the relationship between the macro or collective and micro or individual action (Liska, 1990). The macro sphere referring to broad social structures while micro sphere refers to the agents or individuals. However, both analytical approaches from the macro-micro context is based on social power that are manifested in different narratives. Shamsul focuses on the aspect of colonial knowledge and discourse of ethnic identity formation in Malaysia while Bourdieu focuses on the influence of different forms of capital and its interrelations with different social class groups. While their basis in functionality is different both theories use concepts that allow the researcher to study social phenomenons, form narratives and provide a way to see the world (Brubakar, 2000, p. 37).

\section{References}

Adams, M. (2006). Hybridizing Habitus and Reflexivity: Towards an Understanding of Contemporary Identity? Sociology, 40(3): 511- 528. Retrieved from https://doi.org/10.1177/003803850663672

Block, D. (2013). The structure and agency dilemma in identity and intercultural communication research. Language and Intercultural Communication, 13(2): 126-147. Retrieved from https://doi.org/10.1080/14708477.2013.770863

Bottero, W. (2010). Intersubjectivity and Bourdieusian approaches to 'identity'. Cultural Sociology, 4(1): 3-22. Doi: 10.1177/1749975509356750

Bourdieu, P. (1977a). Outline of a theory of practice. Cambridge: Cambridge University Press; in French 1972).

Bourdieu, P. (1977b). The economics of linguistic exchanges. Social Science Information, 16(6): 645668. Retrieved from https://doi.org/10.1177/053901847701600601

Bourdieu, P. (1977c) 'Symbolic power', in D. Gleeson (ed.), Identity and Structure: Issues in the Sociology of Education (Driffield: Nafferton Books)

Bourdieu, P. (1984). Distinction: A social critique of the judgment of taste (R. Nice, Trans.)

Bourdieu, P. (1990). The logic of practice, Cambridge Polity Press.

Bourdieu, P. (1993). Sociology in question. London: Sage

Bourdieu, P., L. Boltanski and M. de Saint Martin. (1978) 'Changes in social structure and changes in the demand for educaton', inS. Giner and M.S. Archer (eds), Contemporary Europe: Social Structures and Cultural Patterns (London: Routledge \& Kegan Paul

Brubaker, R., \& Cooper, F. (2000). Beyond 'Identity'. Theory and Society, 29(1): 1-47. Retrieved from https://www.jstor.org/stable/3108478

Carlsnaes, W. (1992). The Agency-Structure Problem in Foreign Policy Analysis. International Studies Quarterly, 36(3): 245-270. JSTOR. Retrieved from https://doi.org/10.2307/2600772

Clarke, M. (2000). Rosa Parks' Performativity, Habitus, and Ability to Play the Game. Philosophy Today, 44(Supplement): 160-168. Retrieved from https://doi.org/10.5840/philtoday200044Supplement18

Cockerham, W. C. (2005). Health lifestyle theory and the convergence of agency and structure. Journal of health and social behavior, 46(1): 51-67. Retrieved from http://www.jstor.org/stable/4147653

De Nooy, W., (2003) 'Fields and network analysis: correspondence analysis and social network analysis in the framework of field theory', Poetics, 31 (5-6): 305-327.

DiMaggio, P. (1979). On Pierre Bourdieu. American Journal of Sociology, 84(6): 1460-1474. JSTOR. Retrieved from https://www.jstor.org/stable/2777906?seq=1 
Fabiansson, C. (2015). Young people's societal belonging and perception of social status within networks. Rural Society, 24(1): 85-105. Retrieved from https://doi.org/10.1080/10371656.2014.1001476

Fernandis, G. (2000). Papia, Relijang e Tradisang. The Portuguese Eurasians in Malaysia: Bumiquest, a Search for Self Identity. Lustopie (7). Retrieved from https://www.persee.fr/doc/luso_12570273 2000 num $7 \quad 11375$

Goetze, C. (2017). Pierre Bourdieu's Toolbox: Fields, Power, Practices, and Habitus in theAnalysis of Peacebuilding. In The distinction of peace: a social analysis of peacebuilding. [E-book] (15-39). University of Michigan Press. Retrieved from https://www.jstor.org/stable/j.ctt1qv5nd6.6

Harker, R., Mahar, C., \& Wilkes, C. (Eds.). (1990). An Introduction to the Work of Pierre Bourdieu: The Practice of Theory. Palgrave Macmillan UK. Retrieved from https://doi.org/10.1007/978-1349-21134-0

Hay, C. (2002) 'Globalisation as a Problem of Political Analysis: Restoring Agents to a "Process without a Subject" and Politics to a Logic of Economic Compulsion', Cambridge Review of International Affairs, 15(3): 379-392. Doi: 10.1080/0955757022000010935.

Hilgers, M., \& Mangez, É. (2014). Introduction to Pierre Bourdieu's theory of social fields. In M. Hilgers \& É. Mangez (Eds.) Bourdieu's theory of social fields: concepts and applications, [Ebook] (1-36). Routledge. Retrieved from https://www.researchgate.net/publication/266615346

Jones, S. (1997). The Archaeology of Ethnicity: Constructing Identities in the Past and Present. Routledge.

Kipo, D. (2013). Agency-Structure Relation in Social Sciences: Reflections on Policy Implementation. Asian Social Science, 10(2). Retrieved from https://doi.org/10.5539/ass.v10n2p18

Kupari, H. (2016). Practice, Habitus and Lived Religion. In Lifelong Religion as Habitus: religious practice among displaced Karelian Orthodox women in Finland Chapter 2. [E-book] (10-33). Brill. Retrieved from https://www.jstor.org/stable/10.1163/j.ctt1w8h2mf.6

Lacroix, T. (2012). Designing a structure/agency approach to transnationalism, the international Migration Institute (IMI), IMI working Paper Series 2013, No. 65. Retrieved from https://halshs.archives-ouvertes.fr/halshs-00819982

Lahire, B. (2014). The limits of the field: Elements for a theory of the social differentiation of activities. In M. Hilgers \& E. Mangez (Eds.), Bourdieu's Theory of Social Fields. Concept and application. [e-book] 62- $101 . \quad$ Routledge. $\quad$ Retrieved from https://www.researchgate.net/publication/266615346

Layder, D. (1994). Understanding social theory. Sage.

Levine, H. B. (1999). Reconstructing Ethnicity. Journal of the Royal Anthropological Institute, 5(2): 165. Retrieved from https://www.questia.com/library/journal/1G1-55472990/reconstructingethnicity

Liska, A. E. (1990). The Significance of Aggregate Dependent Variables and Contextual Independent Variables for Linking Macro and Micro Theories. Social Psychology Quarterly 53(4), 292-301. JSTOR. Retrieved from http://www.jstor.org/stable/2786735

Mehdi, R., Hossein, M., Abdulhadi, M. \& Abolfazl, H. (2014). The Relationship between Structure and Agency in Communicative Action Theory. Bulletin of Environment, Pharmacology and Life Sciences, 3(2): 141-149. Retrieved from https://www.semanticscholar.org/paper/TheRelationship-between-Structure-and-Agency-in-Rafiee-

Mirzaei/48aed8fd04d4e28c26495fe1a3b3573d17ae753c

Ngarachu, F. W. (2014). APPLYING PIERRE BOURDIEU'S CONCEPTS OF HABITUS AND FIELD TO THE STUDY OF ETHNICITY IN KENYA. Journal of Language, Technology \& Entrepreneurship in Africa, 5(1): 57-69. Retrieved from https://www.ajol.info/index.php/jolte/article/view/104805

Ong, W. J. (2013). Interfaces of the Word: Studies in the Evolution of Consciousness and Culture (Reprint edition). Cornell University Press.

Pirnajmuddin, H., \& Heidari, E. (2013). Brian Friel's Translations: a Bourdieusian reading. Journal of Language Teaching and Research, 4(4): 741-745. Doi: 10.4304/jltr.4.4.741-745

Pue, G. H. \& Shamsul, A. B. (2012). Peranakan as a Social Concept. (UKM Ethnic Studies Paper Series No. 20 (April). [E-book]. Institute Kajian Etnik, Universiti Kebangsaan Malaysia 43600 Bangi, Selangor D.E., Malaysia. Retrieved from https://www.researchgate.net/publication/317277163 
Reay, D. (1998). Rethinking Social Class: Qualitative Perspectives on Class and Gender. Sociology-the Journal of The British Sociological Association - SOCIOLOGY, 32, 259-275. Retrieved from https://doi.org/10.1177/0038038598032002003

Ritzer, G. (1999). Classical Sociological Theory: $3^{\text {rd }}$ Edition. McGraw-Hill Companies.

Said, E. W. (1978). Orientalism. Pantheon Books. Retrieved from https://books.google.com.my/books?id=dVpxAAAAMAAJ\& sitesec=reviews

Sallaz, J. J., \& Zavisca, J. (2007). Bourdieu in American Sociology, 1980-2004. Annual Review of Sociology, 33(1): 21-41. Retrieved from https://doi.org/10.1146/annurev.soc.33.040406.131627

Savage, M. (2000). Class analysis and social transformation. Open University Press.

Sciulli, D., \& Gerstein, D. (1985). Social Theory and Talcott Parsons in the 1980. Annual Review of Sociology, 11(1): 369-387. Retrieved from https://www.jstor.org/stable/2083299

Scott, W. R. (2008). Institutions and organizations: Ideas and interests. Sage.

Serban, S. (2011). Bourdieu's influence on contemporary thought in the social sciences. Contemporary Readings in Law and Social Justice, 3(2): 248- 253. Retrieved from https://addletonacademicpublishers.com/search-in-crlsj/1411-bourdieu-s-influence-oncontemporary-thought-in-the-social-sciences

Sewell Jr, W. H. (1992). A theory of structure: Duality, agency, and transformation. American journal of sociology, 98(1): 1-29. Retrieved from http://www.jstor.org/stable/2781191

Shamsul A. B. (1999). Identity contestation in Malaysia: A comparative commentary on 'Malayness' and 'Chineseness'. AKADEMIKA, 55(July): 17-37. Retrieved from http://pkukmweb.ukm.my/penerbit/jdem55-01.html

Shamsul, A. B. \& Athi, S. M. (2015). Ethnicity and identity formation: Colonial knowledge, colonial structures and transition. In Routledge Handbook of Contemporary Malaysia, Chapter 21. [Ebook] (.267-278). Taylor and Francis Inc. Retrieved from https://ukm.pure.elsevier.com/en/publications/ethnicity-and-identity-formation-colonialknowledge-colonial-stru

Shamsul, A. B. (1996a). Debating about identity in Malaysia: A discourse analysis. Southeast Asian Studies, 34(3): 476-499. Retrieved from https://ukm.pure.elsevier.com/en/publications/debatingabout-identity-in-malaysia-a-discourse-analysis

Shamsul, A. B. (1996b). 'Nations-of-Intent in Malaysia' in Asian Forms of the Nation, edited by Stein Tonnesson and Han Antlov, London: Curzon 1996 (323-347). Retrieved from https://www.researchgate.net/publication/275956816_'Nations-of-

Intent_in_Malaysia'_in_Asian_Forms_of_the_Nation_edited_by_Stein_Tonnesson_and_Han_A ntlov_London_Curzon_1996

Shamsul, A. B. (2001). A history of an identity, an identity of a history: The idea and practice of 'Malayness' in Malaysia reconsidered. Journal of Southeast Asian Studies, 32(3): 355-366. Retrieved from https://ukm.pure.elsevier.com/en/publications/a-history-of-an-identity-anidentity-of-a-history-the-idea-and-pr

Shamsul, A. B. (2013). Politics of Language and Language of Politics: Theory and practice of the 'Nation-of-Intent' as articulated in Malaysia. UKM Ethnic Studies Paper Series No. 35.

Siddique, S., \& Suryadinata, L. (1981). Bumiputra and Pribumi: Economic Nationalism (Indiginism) in Malaysia and Indonesia. Pacific Affairs, 54(4): 662-687. Retrieved from https://doi.org/10.2307/2757890

Singh, S. (2016). Political Field Dynamics and the Elite's Interest in Democracy: Insights from the Political Elite's Role in Consolidating Indian Democracy. International Journal of Politics, Culture, and Society, 29(2): 183-208. Retrieved from https://doi.org/10.1007/s10767-015-9211$\underline{5}$

Skeggs, B. (1997). Formations of class \& gender: Becoming respectable (Vol. 51). Sage.

Spencer, S. (2006). Race and ethnicity: Culture, identity and representation. [e-book]. Retrieved from http://armytage.net/pdsdata/[Stephen_Spencer]_Race_and_Ethnicity_Identity,_Cu(BookFi.o g).pdf

Swartz, D. (2012). Culture and power: The sociology of Pierre Bourdieu. University of Chicago Press. Sweeney, A. (1987). A Full Hearing: Orality and Literacy in the Malay World. University of California, Berkeley, 1987). Retrieved from https://doi.org/10.2307/1177968

Tan, S. (2011). Understanding the "Structure" and "Agency"; debate in the Social Sciences. Habitus (Undergraduate Journal of the Yale Sociology Department). Retrieved from 
DOI: https://doi.org/10.47405/mjssh.v6i7.869

https://www.academia.edu/576759/Understanding the Structure and Agency debate in the Social Sciences

Tsekeris, C., \& Lydaki, A. (2011). The micro-macro dilemma in sociology: Perplexities and perspectives. Sociologija, 53(1): 67-82. Doi: 10.2298/SOC1101067T

Turner, B. S., \& Wainwright, S. P. (2003). Corps de ballet: The case of the injured ballet dancer. Sociology of Health \& Illness, 25(4): 269-288.

Vandenberghe, F. (2005). Book Review: The Archers: A Tale of Folk (Final Episode?). European Journal of Social Theory, 8(2):227-237. Retrieved from https://doi.org/10.1177/1368431005051765 